\title{
MODELLING MASONRY CREW PRODUCTIVITY USING TWO ARTIFICIAL NEURAL NETWORK TECHNIQUES
}

\author{
İbrahim Halil GEREK ${ }^{\mathrm{a}}$, Ercan ERDIS ${ }^{\mathrm{b}}$, Gulgun MISTIKOGLU ${ }^{\mathrm{c}}$, Mumtaz USMEN ${ }^{\mathrm{d}}$ \\ aAdana Science and Technology University, Engineering and Natural Sciences Faculty, \\ Civil Engineering Department, Adana, Turkey \\ ${ }^{b}$ Mustafa Kemal University, Engineering Faculty, Civil Engineering Department, \\ 31200 Iskenderun, Hatay, Turkey \\ ${ }^{c}$ Mustafa Kemal University, Antakya Vocational College, Antakya, Hatay, Turkey \\ ${ }^{d}$ College of Engineering, Wayne State University, Detroit, MI, USA
}

Received 02 Aug 2012; accepted 17 Oct 2012

\begin{abstract}
Artificial neural networks have been effectively used in various civil engineering fields, including construction management and labour productivity. In this study, the performance of the feed forward neural network (FFNN) was compared with radial basis neural network (RBNN) in modelling the productivity of masonry crews. A variety of input factors were incorporated and analysed. Mean absolute percentage error (MAPE) and correlation coefficient (R) were used to evaluate model performance. Research results indicated that the neural computing techniques could be successfully employed in modelling crew productivity. It was also found that successful models could be developed with different combinations of input factors, and several of the models which excluded one or more input factors turned out to be better than the baseline models. Based on the MAPE values obtained for the models, the RBNN technique was found to be better than the FFNN technique, although both slightly overestimated the masons' productivity.
\end{abstract}

Keywords: productivity modelling, crew productivity, construction industry, masonry, artificial neural networks.

\section{Introduction}

The term productivity is generally used to represent a relationship between outputs and the corresponding inputs used in a production process (Liou, Borcherding 1986). Within the construction industry, productivity commonly refers to labour productivity (Ovararin 2001). Construction labour productivity is one of the most crucial factors affecting the overall performance of any construction project, whether large or small. In recent years, there have been numerous investigations dealing with labour productivity in construction, many of which are related to the quantification of the impact of productivity factors (Kazaz, Ulubeyli 2004; Fayek, Oduba 2005; Ayman et al. 2008; Rateb et al. 2009; Oral et al. 2012). The factors affecting productivity may differ from project to project. Although some factors could have similar influences on the productivity of given tasks, their rate of impact on productivity may vary (Sonmez, Rowings 1998). Several researchers identified the factors affecting labour productivity and developed models to predict it by using different methods. Sanders and Thomas (1991) focused on five project-related factors that significantly affect masonry productivity; namely, work type, building element, design requirements, construction methods, and weather. Ezeldin and Sharara (2006) tried to estimate the productivity of concreting activities by using neural networks, and obtained successful predictive models with strong generalization capabilities.

Determination of realistic productivity values has been a complicated issue due to the complex nature of construction labour productivity. Thus, recent research has drawn on artificial intelligence applications which provide a flexible environment to deal with such complexity. Most of these studies employed supervised methods in Artificial Neural Networks (ANN).

Use of neural networks has been gaining widespread attention in the construction industry to aid in many different applications. Portas and Abourizk (1997) designed a system that utilizes artificial neural networks to estimate formwork productivity for slabs, walls, and columns. Alsugair and Al-Qudrah (1998) developed a neural network to support decision making in pavement maintenance and repairs. Arditi and Tokdemir (1999) attempted to create a neural network that would predict the outcome of construction litigation. Wilmot and Bing (2005) used neural networks for modelling highway construction costs.

Corresponding author: İbrahim Halil Gerek

E-mail: ihgerek@adanabtu.edu.tr 
This paper presents the findings of a research study aimed at the determination of crew productivity in masonry work, and at modelling the relationships between productivity and influencing factors by using two ANN techniques. An understanding of the factors affecting masonry labour productivity would help engineers and architects to design masonry structures that could be constructed more efficiently, while enabling constructors to better estimate, plan, schedule, and manage projects involving masonry. Background information on ANN, FFNN and RBNN techniques is briefly reviewed in the following sections, followed by the research methodology employed, results and discussion, and conclusions of the study.

\section{Artificial neural networks}

The development of artificial neural networks, abbreviated as ANNs has been motivated since their inception by the recognition that human brain computes in an entirely different way from the conventional digital computer. An ANN has the capability to organize its structural constituents, known as neurons, so as to perform certain computations (e.g. pattern recognition, perception) many times faster than digital computers (Haykin 1998). ANNs consist of parallel processing layers of neurons, with each layer being fully connected to the next layer by interconnection strengths, or weights (Kisi 2007b). The ANN techniques can be supervised, unsupervised, or reinforced (Sarangapani 2006).

Many ANN algorithms, such as feed forward neural networks (FFNN), radial basis neural network (RBNN), dynamic networks, learning vector quantization (LVQ) and self-organizing map (SOM) have been adopted in research studies, while being defined at different levels of abstraction, and modelled with a focus on different aspects of neural systems (Hancock 1995; Sudheer, Jain 2003, Oral et al. 2012). For this research study, we chose two supervised techniques; the feed forward neural network (FFNN), and the radial basis neural network (RBNN).

\subsection{Feed forward neural network}

Among the many ANN paradigms, the feed forward backpropagation network (FFNN) is by far the most popular. Detailed theoretical information about FFNN can be found in (Haykin 1998; Cigizoglu 2004). The structure of a typical FFNN model is illustrated in Figure 1. Note that this type of network has one or more hidden layers. Initial estimated weight values are progressively corrected during a training process (at each iteration) that compares predicted outputs with known outputs, and back-propagates any errors to determine the appropriate weight adjustments, which is necessary to minimize the errors. The methodology commonly preferred for adjusting the weights of FFNN is the Levenberg-Marquardt technique, which is considered more powerful than the conventional gradient descent techniques (Hagan, Menhaj 1994; Kisi 2007a).

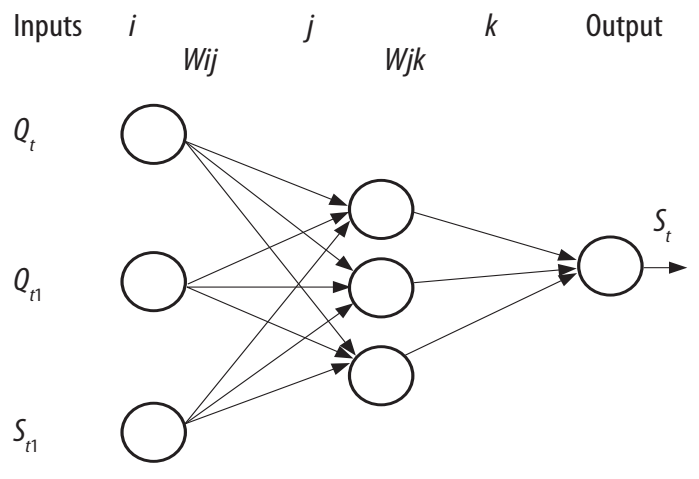

Fig. 1. Structure of a typical FFNN model

\subsection{Radial basis neural network}

The RBNN method was first introduced into the neural network literature by Broomhead and Lowe (1988). The RBNN is composed of two layers whose output nodes consist of a linear combination of the basis functions. The network is also called a localized receptive field network since the basis functions in the hidden layer produce a significant non-zero response to input stimulus only when the input falls within a small localized region of the input space (Lee, Chang 2003). In empirical modelling, according to Bilhan et al. (2010), the transformation of the inputs is essential for "fighting the curse of dimensionality". A local nonlinear radial fixed-shape basis function is used in RBNN for the input transformation (Fig. 2). The Gaussian radial basis functions play the role of regressors after nonlinearly squashing the multidimensional inputs without considering the output space. Since the output layer implements a linear regressor, the weights (parameters) of this regressor are only adjusted. Therefore, these parameters can be determined using the linear least-squares method, which gives an important advantage for convergence.

The basic algorithm and concept of the RBNN is described by Broomhead and Lowe (1988). As covered in this reference, a nonlinear function $h(x, t)$ is referred to as a radial basis function when it depends only on the radial distance, which is given by:

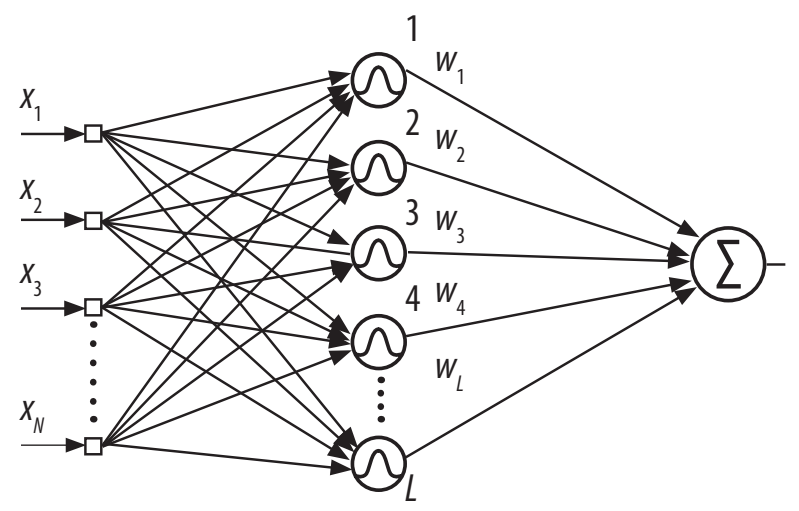

Fig. 2. Structure of a typical RBNN model 


$$
r=\|x-t\|,
$$

where: $x$ is the input variable; and $t$ is the centre of input.

Given $\mathrm{N}$ real numbers $\left\{y_{i} \in R \mid I=1,2, \ldots, N\right\}$ and $\mathrm{N}$ different points $\left\{x_{i} \in R^{n} \mid I=1,2, \ldots, N\right\}$, a function $\mathrm{f}$ can be obtained from $\mathrm{R}^{\mathrm{n}}$ to $\mathrm{R}$ satisfying the interpolation conditions: $f\left(x_{i}\right)=y_{i}, \mathrm{i}=1,2, \ldots, N$. In RBNN $\mathrm{f}$ is chosen from a linear $\mathrm{N}$ dimensional space, depending on the number of data points $\left\{x_{i}\right\}$. The basis of this space is the set of the functions expressed by:

$$
\left\{h\left(\left\|x-x_{i}\right\|\right) \mid i=1,2, \ldots, N\right\},
$$

where $\|$.$\| is the Euclidean norm. Therefore, the solution$ of the interpolation problem has the form:

$$
f(x)=\sum_{i=1}^{N} c_{i} h\left(\left\|x-x_{i}\right\|\right) \text {. }
$$

The unknown coefficients $\mathrm{c}_{i}$ can be found by imposing the interpolation conditions $f\left(x_{i}\right)=y_{i},(\mathrm{i}=1,2, \ldots, N)$ on Eqn (3), and this yields the linear system:

$$
f(x)=\sum_{i=1}^{N} c_{i} h\left(\left\|x_{j}-x_{i}\right\|\right) \mathrm{j}=1,2, \ldots, \mathrm{N} .
$$

Defining the vectors $y, c$ and the symmetric matrix $H$ as $(y)_{j}=y_{j},(c)_{i}=c_{i}$, and $(H)_{i j}=h\left(\left\|x_{j} x_{i}\right\|\right)$, the $c_{i}$ coefficients are given by the equation:

$$
c=H^{-1} y .
$$

Thus, RBNN can be considered as a special case of a linear regression model. The RBNN method only performs linear adjustment of the weights for the radial bases and does not perform parameter learning as is the case for FFNN.

\section{Research methodology}

Masonry crews consist of two types of workers, skilled and unskilled, although there may not be clear demarcations between work tasks performed by these people as they work on the jobsite. Nevertheless, distinct task descriptions are provided for skilled and unskilled labourers by the Turkish Ministry of Environment and Urban Affairs (2008), along with different wage structures for them. In our study we focused on total crew productivity, because we were able to capture onsite production data for the entire crew on a given day as opposed to collecting data pertaining to productions of individual workers. This is consistent with the approach of other researchers (Ezeldin, Sharara 2006; Oral, E. L., Oral, M. 2010).

The aims of this study are twofold: (a) to analyse the relationship between the various input factors listed in Table 1 and the output of masonry crew productivity; and (b) to develop predictive models for crew productivity under the given conditions. To achieve these goals, first standard time study sheets were developed to systematize data collection. Afterwards, the data was organized and refined to establish the factors incorporated in the study. Data used for this research were obtained between September 2006 and September 2008 from randomly selected building construction sites in Turkey. A majority (about 80 percent) of the data was collected from southern provinces (Gaziantep, Osmaniye, Adana, Antalya, Hatay and K. Maraş), and remaining 20 percent came from other regions (Istanbul, Ankara and Adiyaman).

The input factors listed in Table 1 belonged to three categories: labour related factors (numbers of skilled

\begin{tabular}{|c|c|c|c|}
\hline Factor & Abbr. & Type & Values \\
\hline $\begin{array}{l}\text { No. of skilled } \\
\text { laborers }\end{array}$ & SL & Cont. & \\
\hline $\begin{array}{l}\text { No. of unskilled } \\
\text { laborers }\end{array}$ & UL & Cont. & \\
\hline $\begin{array}{l}\text { Daily unit cost of } \\
\text { crew labor }\end{array}$ & UP & Cont. & \\
\hline $\begin{array}{l}\text { Average of crew } \\
\text { age }\end{array}$ & A & Categ. & $\begin{array}{l}1: 18-30 \\
2: 31-35 \\
3: 36-50\end{array}$ \\
\hline $\begin{array}{l}\text { Total experience } \\
\text { of crew }\end{array}$ & EX1 & Categ. & $\begin{array}{l}\text { 1: } 1-120 \mathrm{mo} . \\
\text { 2: 121-202 mo. } \\
\text { 3: 203-300 mo. }\end{array}$ \\
\hline $\begin{array}{l}\text { Experience of } \\
\text { crew members } \\
\text { on same team }\end{array}$ & EX2 & Categ. & $\begin{array}{l}\text { 1: } 0-20 \mathrm{mo} . \\
2: 21-50 \mathrm{mo} . \\
3: 51-80 \mathrm{mo} .\end{array}$ \\
\hline $\begin{array}{l}\text { Experience of } \\
\text { crew members } \\
\text { on particular site }\end{array}$ & EX3 & Categ. & $\begin{array}{l}\text { 1: } 0-5 \mathrm{mo} . \\
2: 6-15 \mathrm{mo} . \\
3: 16-25 \mathrm{mo} .\end{array}$ \\
\hline Wage type & W & Categ. & $\begin{array}{l}\text { 0: Daily } \\
\text { 1: Lump Sum } \\
\text { 2: Weekly }\end{array}$ \\
\hline $\begin{array}{l}\text { Days worked in } \\
\text { a week }\end{array}$ & WD & Cont. & \\
\hline Daily work hours & $\mathrm{WH}$ & Cont. & \\
\hline Over time (h) & OT & Cont. & \\
\hline Break time (h) & $\mathrm{BR}$ & Cont. & \\
\hline Accommodation* & $\mathrm{AC}$ & Categ. & $\begin{array}{l}\text { 0: On site } \\
\text { 1: Off Site } \\
\text { (<29 minute) } \\
\text { 2: Off Site } \\
(>30 \text { minute) }\end{array}$ \\
\hline Wall type & WT & Categ. & $\begin{array}{l}\text { 1: Brick } \\
\text { 2: Iso-Brick } \\
\text { 3: Briquette } \\
\text { 4: Aerated Conc. } \\
\text { (AAC) } \\
\text { 5: Light Brick }\end{array}$ \\
\hline Mortar type & MT & Categ. & $\begin{array}{l}\text { 1: Pre-Mixed } \\
\text { 2: On site }\end{array}$ \\
\hline $\begin{array}{l}\text { Productivity } \\
(\mathrm{m} 2 / \mathrm{h})\end{array}$ & $\mathrm{P}$ & Cont. & \\
\hline
\end{tabular}
and unskilled labourers, average crew age, total crew experience, experience of crew members on same team, and experience of crew members on particular site); contract-

Table 1. Crew productivity factors considered in the study

* Where workers stay overnight 
based factors (daily unit cost of crew labour, wage type, days worked in a week, daily work hours, over time, break time and accommodation); and technical factors (wall type and mortar type). The factors were established as continuous or categorical variables. All data analysis using FFNN and RBNN was performed by MATLAB software. The neural networks instruments were configured and tuned with different network structures and parameters in order to achieve the best prediction performances in modelling crew productivity. Crew productivity was determined for 147 crews. The data were randomized and divided into two parts, training and testing. The first 110 cases were used for training and the remaining 37 cases were used for testing, representing a $75 \%$ to $25 \%$ split.

First, training input and output data were normalized to zero mean and unit variance following the procedure suggested by Lawrence et al. (1997). Before applying the ANN techniques to the data, the training input and output values were normalized using the equation:

$$
x=a \frac{x_{i}-x_{\min }}{x_{\max }-x_{\min }}+b,
$$

where $\mathrm{x}_{\min }$ and $\mathrm{x}_{\max }$ denote the minimum and maximum values of the training and testing data (Eqn (6)).

Note that different numbers can be assigned for scaling factors $a$ and $b$. There are no fixed rules as to which standardization approach should be used in particular circumstances (Dawson, Wilby 1998). In this study, the $\mathrm{a}$ and $\mathrm{b}$ were taken as 0.6 and 0.2 , respectively.

Different FFNN and RBNN architectures were tried to determine the appropriate model structure. The FFNN technique was used with two hidden layers, and the number of hidden nodes was determined using a trial and error approach. The saturating linear and linear activation functions were used for the hidden and output nodes, respectively. The FFNN networks training were stopped after 50 epochs when the variation of error came down to the targeted error value $\left(10^{-20}\right)$.

Different numbers of hidden layer neurons, as well as values of spread constants, were examined for the RBNN models. The optimal hidden layer neuron number for minimum mean square error (MSE) was found to be 11 , while the spread constant value came out to be 2. The model prediction abilities were evaluated based on the mean absolute percentage errors (MAPE) and correlation coefficient (R). The MSE, MAPE and R are defined in the following equations:

$$
\begin{aligned}
& M S E=\frac{\sum_{i=1}^{N}\left(Y_{i \text { observed }}-Y_{\text {iforecast }}\right)^{2}}{N} ; \\
& R=\left\lfloor\frac{N \sum_{i=1}^{N} Y_{i \text { observed }} Y_{i \text { forecast }}-\left(\sum_{i=1}^{N} Y_{i \text { observed }}\right)\left(\sum_{i=1}^{N} Y_{i \text { forecast }}\right)}{\sqrt{\left[N \sum_{i=1}^{N} Y_{i}^{2}{ }_{\text {observed }}-\left(\sum_{i=1}^{N} Y_{\text {iobserved }}\right)^{2}\right] *\left[N \sum_{i=1}^{N} Y_{i \text { forecast }}^{2}-\left(\sum_{i=1}^{N} Y_{i f o r e c a s t}\right)^{2}\right]}}\right\rfloor \\
& M A P E=\frac{\sum_{i=1}^{N}\left(\left|Y_{i \text { forecast }}-Y_{\text {iobserved }}\right| / Y_{\text {iobserved }}\right)}{N}
\end{aligned}
$$

In these equations, $N$ is the number of data sets and $Y_{i}$ values denote values of observed and forecast productivity.

It should be noted that the (1-MAPE) value shows the prediction accuracy of a model (Oral, E. L., Oral, M. 2010). The FFNN technique produced 32 different productivity models, eleven of which were considered successful according to the criteria selected based on (1-MAPE) values being greater than $0.85(85 \%)$. A value of 0.75 was considered acceptable for correlation $\mathrm{R}$ the case for all models. The RBNN technique produced ten valid models following a similar process.

\section{Results and discussion}

The results of data analysis using FFNN and RBNN are presented in Tables 2 and 3. Each row in the tables lists the input and output results for a particular model and the inputs represent the productivity factors for that model. These were determined by systematically omitting/ subtracting individual factors, or group of factors, from the entire list. The changes in MAPE values signify the improvements in the models from the effects of productivity factors. Model success level is based on lower values of (MAPE), which translates to higher values of (1-MAPE).

Table 2 for FFNN shows that model FF31 is the most successful one based on a (1-MAPE) value of $86.77 \%$. The best model for RBNN is Model RB25 as given in Table 3 with a (1-MAPE) value of $92.64 \%$. The models presented in Tables 2 and 3 are ranked in order from high to low success level. Based on mean MAPE values computed for the two ANN techniques employed in this study, it can be stated that the RBNN technique yields better results. All $\mathrm{R}$ values are in the acceptable range.

It is also noted that RB1 and FF1 (indicated in bold letters in Table 2 and Table 3) are the baseline models which embody all of the input factors. Our results did not show a major difference in MAPE values for the baseline models constructed by the two techniques. However, one can argue that the models with higher (1-MAPE) values compared to the baseline models are the ones to be recommended for use because they improve on forecasting power. From this viewpoint, the RBNN technique provides an advantage over FFNN by availing a larger number of models (obtained by subtracting selected input factors from a given model) that are better than the baseline model. 
Table 2. Productivity modeling results for FFNN

\begin{tabular}{|c|c|c|c|c|}
\hline \multirow{2}{*}{$\begin{array}{l}\text { Model } \\
\text { no. }\end{array}$} & \multirow{2}{*}{ Inputs } & \multirow{2}{*}{$\begin{array}{l}\text { Omitted } \\
\text { input }\end{array}$} & \multicolumn{2}{|c|}{$\begin{array}{l}\text { Testing } \\
\text { results }\end{array}$} \\
\hline & & & $\begin{array}{c}\text { MAPE, } \\
\%\end{array}$ & $\mathrm{R}$ \\
\hline FF19 & $\begin{array}{l}\text { SL, UL, UP, A, EX1, } \\
\text { EX2, EX3, WD, WH, } \\
\text { OT, BR, WT, MT }\end{array}$ & $\mathrm{W}, \mathrm{AC}$ & 12.366 & 0.858 \\
\hline FF31 & $\begin{array}{l}\text { SL, UL, UP, A, EX1, } \\
\text { EX2, EX3, W, WD, WH, } \\
\text { BR, AC, WT, MT }\end{array}$ & OT & 13.225 & 0.859 \\
\hline FF30 & $\begin{array}{l}\text { SL, UL, UP, A, EX1, } \\
\text { EX2, EX3, W, WD, WH, } \\
\text { OT, AC, WT, MT }\end{array}$ & $\mathrm{BR}$ & 13.756 & 0.791 \\
\hline FF1 & $\begin{array}{c}\text { SL, UL, UP, A, EX1, } \\
\text { EX2, EX3, W, WD, } \\
\text { WH, OT, BR, AC, } \\
\text { WT, MT }\end{array}$ & - & 14.319 & 0.861 \\
\hline FF29 & $\begin{array}{l}\text { SL, UL, UP, A, W, } \\
\text { WD, WH, OT, BR, } \\
\text { AC, WT, MT }\end{array}$ & $\begin{array}{l}\text { EX1 } \\
\text { EX2 } \\
\text { EX3 }\end{array}$ & 14.359 & 0.799 \\
\hline FF23 & $\begin{array}{l}\text { UP, A, EX1, EX2, } \\
\text { EX3, W, WD, WH, OT, } \\
\text { BR, AC, WT, MT }\end{array}$ & SL, UL & 14.441 & 0.765 \\
\hline FF20 & $\begin{array}{l}\text { SL, UL, UP, A, EX1, } \\
\text { EX2, EX3, W, WD, } \\
\text { WH, OT, BR, } \\
\text { WT, MT }\end{array}$ & $\mathrm{AC}$ & 14.477 & 0.769 \\
\hline FF24 & $\begin{array}{l}\text { SL, UL, A, EX1, } \\
\text { EX2, EX3, W, WD, } \\
\text { WH, OT, BR, AC, } \\
\text { WT, MT }\end{array}$ & UP & 14.942 & 0.778 \\
\hline FF18 & $\begin{array}{l}\text { SL, UL, UP, A, EX1, } \\
\text { W, WD, WH, OT, } \\
\text { BR, WT, MT }\end{array}$ & $\begin{array}{c}\mathrm{EX} 2, \\
\mathrm{EX} 3, \mathrm{AC}\end{array}$ & 15.125 & 0.773 \\
\hline FF17 & $\begin{array}{l}\text { SL, UL, UP, A, EX1, } \\
\text { EX2, EX3, W, WD, } \\
\text { OT, AC, WT, MT }\end{array}$ & WH, BR & 15.204 & 0.786 \\
\hline FF28 & $\begin{array}{l}\text { SL, UL, UP, EX2, } \\
\text { EX3, W, WD, WH, } \\
\text { OT, BR, AC, } \\
\text { WT, MT }\end{array}$ & $\mathrm{A}, \mathrm{EX} 1$ & 15.538 & 0.799 \\
\hline & Mean value & & 14.341 & 0.803 \\
\hline
\end{tabular}

On the other hand, results given in Tables 2 and 3 reveal that there are six models having common sets of inputs and excluding certain common factors. An example is model number RB24 where daily unit cost of crew labour (UP) is omitted. The low MAPE value implies that UP has less influence on productivity compared to the other input factors of the model. This is true for FF 24 , but at a lower accuracy level. The results for the other three pairs of models (FF 30 and RB30, FF31 and RB31, FF19 and RB19) also indicate that the omitted factors (OT, BR, W and AC) have minor effects on the out-
Table 3. Productivity modeling results for RBNN

\begin{tabular}{|c|c|c|c|c|}
\hline \multirow{2}{*}{$\begin{array}{c}\text { Model } \\
\text { no. }\end{array}$} & \multirow{2}{*}{ Inputs } & \multirow{2}{*}{$\begin{array}{l}\text { Omitted } \\
\text { input }\end{array}$} & \multicolumn{2}{|c|}{$\begin{array}{l}\text { Testing } \\
\text { results }\end{array}$} \\
\hline & & & $\begin{array}{c}\text { MAPE, } \\
\%\end{array}$ & $\mathrm{R}$ \\
\hline RB24 & $\begin{array}{c}\text { SL, UL, A, EX1, } \\
\text { EX2, EX3, W, } \\
\text { WD, WH, OT, } \\
\text { BR, AC, WT, MT }\end{array}$ & UP & 10.152 & 0.928 \\
\hline RB30 & $\begin{array}{c}\text { SL, UL, UP, A, } \\
\text { EX1, EX2, EX3, } \\
\text { W, WD, WH, } \\
\text { OT, AC, WT, MT }\end{array}$ & BR & 10.384 & 0.962 \\
\hline RB31 & $\begin{array}{c}\text { SL, UL, UP, A, } \\
\text { EX1, EX2, EX3, } \\
\text { W, WD, WH, } \\
\text { BR, AC, WT, MT }\end{array}$ & OT & 11.772 & 0.921 \\
\hline $\mathrm{RB} 25$ & $\begin{array}{l}\text { SL, UL, UP, EX1, } \\
\text { EX2, EX3, W, } \\
\text { WD, WH, OT, } \\
\text { BR, AC, WT, MT }\end{array}$ & A & 14.068 & 0.880 \\
\hline RB19 & $\begin{array}{c}\text { SL, UL, UP, A, } \\
\text { EX1, EX2, EX3, } \\
\text { WD, WH, OT, } \\
\text { BR, WT, MT }\end{array}$ & $\mathrm{W}, \mathrm{AC}$ & 14.228 & 0.814 \\
\hline $\mathrm{RB} 20$ & $\begin{array}{c}\text { SL, UL, UP, A, } \\
\text { EX1, EX2, EX3, } \\
\text { W, WD, WH, OT, } \\
\text { BR, WT, MT }\end{array}$ & $\mathrm{AC}$ & 14.372 & 0.887 \\
\hline RB1 & $\begin{array}{l}\text { SL, UL, UP, A, } \\
\text { EX1, EX2, EX3, } \\
\text { W, WD, WH, OT, } \\
\text { BR, AC, WT, MT }\end{array}$ & - & 14.378 & 0.794 \\
\hline RB33 & $\begin{array}{l}\text { SL, UL, UP, A, } \\
\text { EX1, EX2, EX3, } \\
\text { W, WD, WH, OT, } \\
\text { BR, AC, WT }\end{array}$ & MT & 14.430 & 0.778 \\
\hline RB29 & $\begin{array}{l}\text { SL, UL, UP, A, W, } \\
\text { WD, WH, OT, } \\
\text { BR, AC, WT, MT }\end{array}$ & $\begin{array}{l}\text { EX1, } \\
\text { EX2, } \\
\text { EX3 }\end{array}$ & 14.784 & 0.828 \\
\hline RB18 & $\begin{array}{l}\text { SL, UL, UP, A, } \\
\text { EX1, W, WD, } \\
\text { WH, OT, BR, } \\
\text { WT, MT }\end{array}$ & $\begin{array}{c}\mathrm{EX} 2 \\
\mathrm{EX} 3 \\
\mathrm{AC}\end{array}$ & & 0.807 \\
\hline & Mean value & & 14.955 & 0.860 \\
\hline
\end{tabular}

put (crew productivity value) of the respective models. In addition, in model number FF19, where wage (W) and accommodation (AC) are omitted, it is seen that these factors have less influence on productivity than the other input factors.

Further data analysis encompassed comparisons between the observed and estimated productivity values for baseline models FF1 and RB1, and the results from the testing phases of the analyses are plotted in Figures 3, 4, 5 and 6. It can be clearly discerned from Figure 3 that there are varying degrees of disagreements between the 


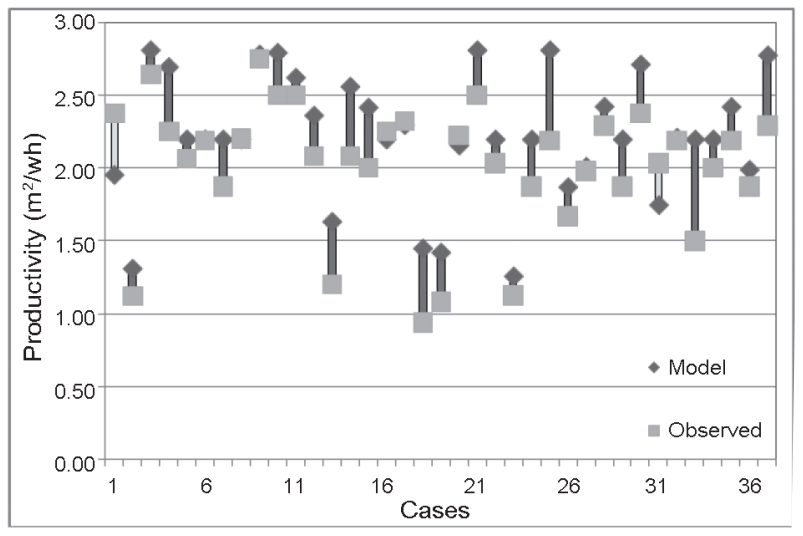

Fig. 3. The observed and estimated crew productivity for FF1

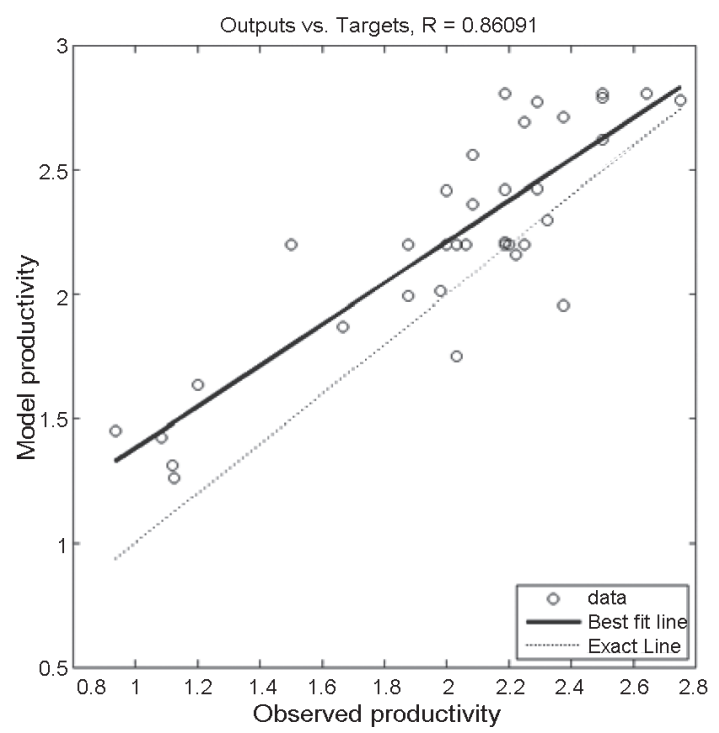

Fig. 4. A scatter plot of FF1

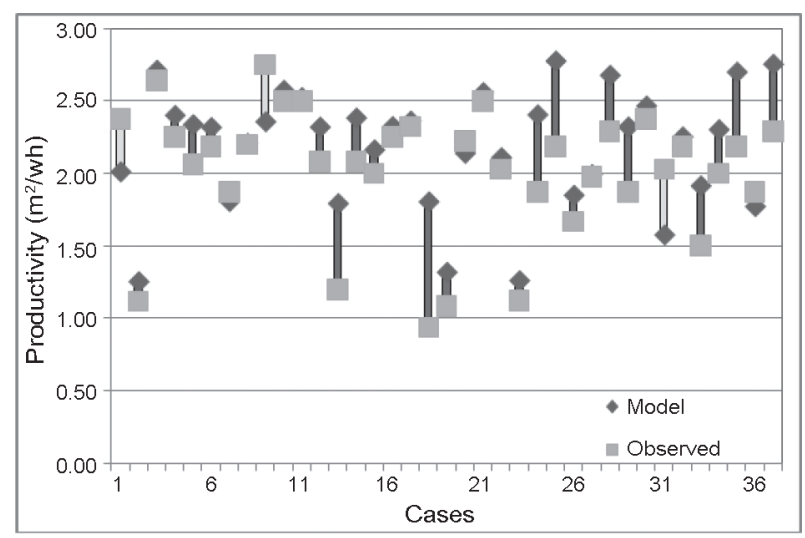

Fig. 5. The observed and estimated crew productivity for baseline model RB1 model estimates or forecasts and observed productivity values for FF1. The figure shows how the differences between forecasted and observed values are distributed over the set of 37 cases included in analysis. In a majority of the cases, the model overestimates productivity, although the MAPE value is small and within the accepted range. Figure 4 is a scatter plot of the same data, aimed at establishing the line of best fit to the data, indicated by the solid line in the figure. The dotted line below is the exact line which indicates a perfect fit, i.e. all observed and estimated values are equal. The slope of this line gives the magnitude of the R value. For the FF1 baseline model, an $R$ value of 0.86 indicates a good fit for this model.

The observed and estimated productivity results for the baseline model RB1 are plotted in Figure 5. It is seen in this the figure that similar to FF1 results illustrated in Figure 3, the model estimates are mostly over the observed values of productivity. However, the MAPE value is still small.

A scatter plot for RB1 appears in Figure 6, which shows the best fit and exact lines for this model. The lines show a tendency to come closer and merge at higher observed (and predicted) productivity values, suggesting that the model accuracy is better at high productivity levels. A R value of 0.794 is indicative of a good model fit.

Table 4 displays the individual input factors affecting productivity in ranking order based on MAPE results. The higher the ranking for a given factor, the lower is the influence on model accuracy. Note that whereas the ranking numbers are in ascending order for RBNN, the FFNN rankings follow the factor rather than following any particular order.

A noteworthy observation from Table 4 is that WT and WD have the highest ranks in both RBNN and FFNN, which means they yield the highest level of influence on model accuracy and predictive power. Interestingly, MT surfaces as an important factor in the FNNN case, but not

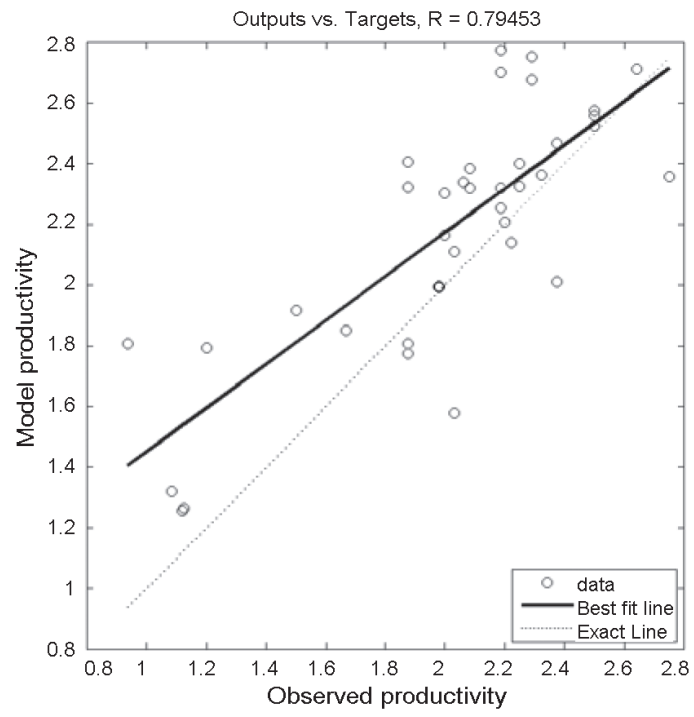

Fig. 6. A scatter plot of baseline model RB1 
Table 4. Ranking of factors affecting crew productivity

\begin{tabular}{lccc}
\hline \multirow{2}{*}{ Factor } & Abbr. & \multicolumn{2}{c}{ Rank } \\
\cline { 3 - 4 } & & RBNN & FFNN \\
\hline $\begin{array}{l}\text { Daily unit cost of crew } \\
\text { labor }\end{array}$ & UP & 1 & 10 \\
\hline Break time & BR & 2 & 3 \\
\hline Over time & OT & 3 & 2 \\
\hline Average of crew age & A & 4 & 12 \\
\hline Wage type & W & 5 & 1 \\
\hline Accommodation & AC & 6 & 9 \\
\hline Mortar type & MT & 7 & 14 \\
\hline $\begin{array}{l}\text { Experience of crew } \\
\text { members on same team }\end{array}$ & EX2 & 8 & 4 \\
\hline Total experience of crew & EX1 & 9 & 5 \\
\hline $\begin{array}{l}\text { Experience of crew } \\
\text { members on particular }\end{array}$ & EX3 & 10 & 6 \\
site & & & \\
\hline No. of laborers & SL & 11 & 7 \\
\hline No. of laborers & UL & 12 & 8 \\
\hline Daily work hours & WH & 13 & 11 \\
\hline Wall type & WT & 14 & 15 \\
\hline Days worked in a week & WD & 15 & 13 \\
\hline
\end{tabular}

as much for RBNN. Another useful observation that can be made from the table relates to the role of experience in masonry crew productivity. Three types of experience related factor, EX1, EX2 and EX3 were included in the study. The results show that experience of crew members on the particular site (EX3) has larger influence on productivity than the other two types of experience factors.

\section{Conclusions}

The accuracy of two different neural network techniques, FFNN and RBNN, has been evaluated for the estimation of productivity for masonry crews working in building construction. A total of 147 cases were used to generate the models. Comparison of results between the two techniques indicated that the mean absolute percentage errors (MAPE) for the RBNN models were lower than those of the FFNN models, indicating a better performance. The results suggest that the FFNN and RBNN techniques can be successfully used in estimation of crew productivity in the construction sector.

It was additionally established that successful models could be developed with different combinations of input factors, and several of the models which excluded one or more input factors turned out to be better than the baseline models. It is possible to examine the models in more detail by plotting observed and estimated values of productivity, which lends itself to comparisons on a case by case basis, as well as establishing the lines of best fit. When this was done for the baseline models, it was found that these models slightly overestimate crew productivity, but overall the MAPE values are small and in the accepted range.
Research results showed that model accuracy and predictive power were not significantly affected by the exclusion of UP, BR and OT for RB24, RB30 and RB31 models. On the other hand, the results showed that when WD, WT and WH were excluded, predictive power of the corresponding models was affected considerably. The information derived from the research presented in this paper should be particularly valuable for site managers and project managers, who might like to focus on the important productivity factors and not dwell on the less important ones in planning project activities. It must be kept in mind, however, that the models developed in this research are derived from data collected in certain geographical regions in Turkey, and they may need to be adjusted according to the differences in masonry and plastering work practices elsewhere. Yet, the models presented here should have additional value in allowing future researchers to conduct comparative analysis with productivity models based on data from other localities.

\section{Acknowledgements}

This paper is based on research work undertaken as part of a larger project (106M055) sponsored by TÜBİTAK (The Scientific and Technical Research Council of Turkey). This support is gratefully acknowledged. The authors would like to express their gratitude to the other members of the research team (E. Oral, M. Oral, M. E. Ocal, and O. Paydak) for their invaluable contributions to the project.

\section{References}

Alsugair, A. M.; Al-Qudrah, A. A. 1998. Artificial neural network approach for pavement maintenance, Journal of Computing in Civil Engineering 12(4): 249-255.

http://dx.doi.org/10.1061/(ASCE)0887-3801(1998)12:4(249)

Arditi, D.; Tokdemir, O. B. 1999. Comparison of case-based reasoning and artificial neural networks, Journal of Computing in Civil Engineering 13(3): 162-169.

http://dx.doi.org/10.1061/(ASCE)0887-3801(1999)13:3(162)

Ayman, H. A.; Rateb, S. J.; Sweis, G. J.; Thomas, H. R. 2008. Factors affecting baseline productivity in masonry construction: a comparative study in the US, UK and Jordan, Architectural Science Review 51(2): 146-152. http://dx.doi.org/10.3763/asre.2008.5118

Bilhan, O.; Emiroglu, M. E.; Kisi, O. 2010. Application of two different neural network techniques to lateral outflow over rectangular side weirs located on a straight channel, Advances in Engineering Software 41(6): 831-837. http://dx.doi.org/10.1016/j.advengsoft.2010.03.001

Broomhead, D.; Lowe, D. 1988. Multivariable functional interpolation and adaptive networks, Complex Systems 2: 321-355.

Cigizoglu, H. K. 2004. Estimation and forecasting of daily suspended sediment data by multi-layer perceptrons, Advances in Water Resources 27(2): 185-195. http://dx.doi.org/10.1016/j.advwatres.2003.10.003

Dawson, W. C.; Wilby, R. 1998. An artificial neural network approach to rainfall-runoff modelling, Hydrological Sciences Journal 43(1): 47-66.

http://dx.doi.org/10.1080/02626669809492102 
Ezeldin, A. S.; Sharara, L. M. 2006. Neural networks for estimating the productivity of concreting activities, Journal of Construction Engineering and Management 132(6): 650-656.

http://dx.doi.org/10.1061/(ASCE)0733-9364(2006)132:6(650)

Fayek, A. R.; Oduba, A. 2005. Predicting industrial construction labour productivity using fuzzy expert systems, Journal of Construction Engineering and Management 131(8): 938-941.

http://dx.doi.org/10.1061/(ASCE)0733-9364(2005)131:8(938)

Hagan, M. T.; Menhaj, M. B. 1994. Training feed forward networks with the marquardt algorithm, IEEE Transactions on Neural Networks 6: 861-867.

Hancock, M. F. 1995. Near and long-term load prediction using radial basis function networks, in Applications of Neural Networks in Environment, Energy and Health, World Scientific, Singapore, 108-122.

Haykin, S. 1998. Neural networks. A comprehensive foundation. $2^{\text {nd }}$ ed. Upper Saddle River (NJ), Prentice-Hall. 842 p.

Kazaz, A.; Ulubeyli, S. 2004. A different approach to construction labour in Turkey: comparative productivity analysis, Building and Environment 39(1): 93-100. http://dx.doi.org/10.1016/j.buildenv.2003.08.004

Kisi, O. 2007a. Stream flow forecasting using different artificial neural network algorithms, Journal of Hydrologic Engineering, ASCE 12(5): 532-539.

http://dx.doi.org/10.1061/(ASCE)1084-0699(2007)12:5(532)

Kisi, O. 2007b. Development of Streamflow-Suspended Sediment Rating Curve Using a Range Dependent Neural Network, International Journal of Science \& Technology 2(1): 49-61.

Lawrence, S.; Back, A. D.; Tsoi, A. C.; Giles, C. L. 1997. On the distribution of performance from multiple neural network trials, IEEE Transactions on Neural Networks 8(6): 1507-1517. http://dx.doi.org/10.1109/72.641472

Lee, G. C.; Chang, S. H. 2003. Radial basis function networks applied to DNBR calculation in digital core protection systems, Annals of Nuclear Energy 30(15): 1561-1572. http://dx.doi.org/10.1016/S0306-4549(03)00099-9

Liou, F.; Borcherding, J. D. 1986. Work sampling can predict unit rate productivity, Journal of Construction Management and Management ASCE 112(1): 90-103.
Oral, E. L.; Oral, M. 2010. Predicting construction crew productivity by using self organizing maps, Automation in Construction 19(6): 791-797. http://dx.doi.org/10.1016/j.autcon.2010.05.001

Oral, M.; Oral, E.; Aydın, A. 2012. Supervised vs. unsupervised learning for construction crew productivity prediction, Automation in Construction 22: 271-276. http://dx.doi.org/10.1016/j.autcon.2011.09.002

Ovararin, N. 2001. Quantifying productivity loss due to field disruptions in masonry construction. PhD Dissertation Thesis, Faculty of the Graduate School, University of Texas.

Portas, J.; Abourizk, S. 1997. Neural network model for estimating construction productivity, Journal of Construction Engineering and Management 123(4): 399-410.

http://dx.doi.org/10.1061/(ASCE)0733-9364(1997)123:4(399)

Rateb, S. J.; Sweis, G. J.; Ayman, H. A.; Malek, A. R. 2009. Modelling the variability of labour productivity in masonry construction, Jordan Journal of Civil Engineering 3(3): 197-212.

Sanders, S. R.; Thomas, H. R. 1991. Factors affecting Masonry Labour Productivity, Journal of Construction Engineering and Management 117(4): 626-644.

http://dx.doi.org/10.1061/(ASCE)0733-9364(1991)117:4(626)

Sarangapani, J. 2006. Neural network control of nonlinear discrete-time systems. Taylor \& Francis Group. 624 p. http://dx.doi.org/10.1201/9781420015454

Sonmez, R.; Rowings, J. E. 1998. Construction labour productivity modelling with neural networks, Journal of Construction Engineering and Management 124(6): 498-504.

http://dx.doi.org/10.1061/(ASCE)0733-9364(1998)124:6(498)

Sudheer, K. P.; Jain, S. K. 2003. Radial Basis Function Neural Network for Modelling Rating Curves, Journal of Hydrologic Engineering 8(3): 161-164.

http://dx.doi.org/10.1061/(ASCE)1084-0699(2003)8:3(161)

Wilmot, C. G.; Bing, M. 2005. Neural network modelling of highway construction costs, Journal of Construction Engineering and Management 131: 765-771.

http://dx.doi.org/10.1061/(ASCE)0733-9364(2005)131:7(765)

Ibrahim Halil GEREK. He is an Assistant Professor of Civil Engineering in the Engineering and Natural Sciences Faculty at Adana Science and Technology University. He is a member of Chamber of Civil Engineers of Turkey, and is actively involved in construction management areas. He received his $\mathrm{MS}$ and $\mathrm{PhD}$ degrees in Civil Engineering at the Cukurova University between 2001 and 2010 years, respectively.

Ercan ERDIS. He is an Assistant Professor of Civil Engineering in the Faculty of Engineering at Mustafa Kemal University. He is a member of Chamber of Civil Engineers of Turkey, and is actively involved in construction management areas. He received his MS and PhD degrees in Civil Engineering at the Mustafa Kemal University in 2001 and Cukurova University in 2004, respectively.

Gulgun MISTIKOGLU. He is an Assistant Professor of Civil Engineering in the Antakya Vocational College at Mustafa Kemal University. He is a member of Chamber of Civil Engineers of Turkey, and is actively involved in construction management areas. He received his MS and PhD degrees in Civil Engineering at the Cukurova University between 1987 and 2001 years, respectively.

Mumtaz USMEN. Currently, he is a Professor at the College of Engineering at Wayne State University. He served as Interim Dean and Chairman of the Civil and Environmental Engineering Department at Wayne State University from 1989 to 2009 . Prior to coming to Wayne State, he was a Professor of Civil Engineering at West Virginia University, Morgantown, WV, where he established and directed a NIOSH sponsored Center for Excellence on Construction Safety. He specializes in construction engineering and management with a focus on site safety, quality, ethics, leadership, and organizational improvement. 